\title{
МЕТОДИЧЕСКОЕ ОБЕСПЕЧЕНИЕ ИНТЕРАКТИВНЫХ ЗАНЯТИЙ В ВЫСШЕЙ ШКОЛЕ
}

\author{
В. Г. Мамчук \\ Московский гуманитарный университет
}

\begin{abstract}
Аннотация: В статье рассматриваются формы интерактивного обучения, реализуемого для подготовки специалистов в высшей школе в обязательном порядке в свете требований Федерального государственного образовательного стандарта. Предлагается алгоритм проведения интерактивных занятий как элемент методического обеспечения в системе высшего образования.

Ключевые слова: активное обучение; интерактивное обучение; Федеральный государственный образовательный стандарт высшего образования; метод интерактивного обучения, алгоритм проведения интерактивного занятия
\end{abstract}

\section{METHODOLOGICAL SUPPORT FOR INTERACTIVE LESSONS IN HIGHER EDUCATION}

\author{
V. G. Mamchuk \\ Moscow University for the Humanities
}

\begin{abstract}
The article discusses the forms of interactive teaching implemented in higher education for training specialists due to the requirements of the Federal State Educational Standard of the Russian Federation. An algorithm is proposed for teaching interactive classes as an element of methodological support in the higher education system.
\end{abstract}

Keywords: active teaching; interactive teaching; Federal State Educational Standard for Higher Education; interactive teaching method, algorithm of teaching interactive classes

Образовательная траектория современной педагогики, подкрепленная Федеральным государственным образовательным стандартом высшего образования (ФГОС ВО), выдвигает в качестве одного из важнейших требований к образовательному процессу применение активного и интерактивного обучения в качестве инструмента формирования и развития компетенций обучающихся. Особое внимание уделяется необходимости систематического использования активных и интерактивных форм обучения в образовательном процессе. Так, в соответствии с образовательным стандартом третьего поколения, доля занятий, проводимых с применением интерактивных методов обучения должна составлять не менее 25\% по программам бакалавриата и не менее 40\% по программам магистратуры.

Введение интерактивных форм обучения в образовательный процесс не только способствует улучшению подготовки современных студентов, но и позволяет педагогу вовлечь студентов в изучение предмета при помощи новых форм учебнопознавательной деятельности (Солодухина, 2011). Для достижения поставленной цели необходимо создать условия для парной или групповой работы, реализации проектов, проведения ролевых игр, работы с различными видами информационных источников, способствующей активным интеракциям участников. 
Для начала, уточним, что именно следует понимать под активными и интерактивными методами обучения. В отличие от традиционной формы ведения занятий, на занятиях, проведенных в интерактивной форме, обучающиеся не являются пассивными слушателями, а, наоборот, активно вносят собственный вклад в решение проблемы при помощи обмена знаниями, опытом, а также мозгового штурма. На данный момент между активными и интерактивными методами обучения отсутствует четкая грань, вследствие чего одни и те же методы могут причисляться как к разряду активных, так и интерактивных.

Например, В.Н.Кругликов считает, что активное обучение есть не что иное, как организация и ведение образовательного процесса, направленные на активизацию учебно-познавательной деятельности обучающихся посредством применения широкого спектра дидактических и организационно-управленческих средств, методов активизации (Кругликов, 1998). В одной из своих статей он приходит к выводу, что интерактивное обучение в его современном значении следует рассматривать, с одной стороны, как обучение, в основе которого лежит взаимодействие, с другой стороны, как обучение через общение при помощи внедрения компьютерных технологий в образовательный процесс (Кругликов, 2013: 67).

На данный момент образовательные технологии проведения контактной работы со студентами можно разделить на три формы: пассивную, активную и интерактивную. При использовании пассивной формы контактной работы преподаватель занимает главенствующую позицию в аудитории. Студенты являются пассивными слушателями, а он целиком и полностью руководит ходом занятия. Традиционная лекция является хорошим примером пассивной формы контактной работы со студентами. Педагог излагает подготовленный материал, в то время как студенты составляют конспект либо просто исполняют роль слушателей. Активная формаконтактнойработы, в своюочередь,направленанаактивноеучастиестудентов в процессе обучения и подразумевает более глубокое погружение слушателей в познавательную деятельность. Главным примером использования активной формы контактной работы может являться практическое или семинарское занятие в его традиционной форме. В этом случае роль студентов меняется. Студент и педагог находятся в равнозначных позициях, способствующих открытому диалогу сторон в решении вопросов профессиональной направленности. Интерактивная форма, в отличие от предыдущих, добавляет в образовательный процесс еще один значимый элемент - активное взаимодействие между студентами.

Учитывая, что интеракция (лат. inter - между, actio - деятельность) - это взаимодействие людей в процессе общения, например, в режиме беседы, диалога с кем-либо, можно сделать вывод, что интерактивные методы обучения ориентированы на широкое взаимодействие студента не только с преподавателем, но и с другими студентами. Интерактивные методы базируются на принципах взаимодействия, активности, полагании на групповой опыт, обязательности наличия обратной связи (Двуличанская, 2011). Роль преподавателя на занятии, проходящем в интерактивной форме, сводится к представлению материала в наиболее интересной и эффективной форме с последующим наставничеством в вопросах исследовательской деятельности обучающихся. Таким образом, активная деятельность педагога отходит на второй план, уступая место студенческой 
активности и создавая благоприятные условия для возникновения инициативы среди обучающихся (Панина, Вавилова, 2008: 9). Студенты сталкиваются с проблемой правильного построения коммуникации, коллективного поиска решения поставленной задачи, преодоления конфликтов, возникающих в процессе обсуждения, а также поиска компромиссов. Преподаватель, в свою очередь, должен заблаговременно подготовить план и содержание занятия, продумать задания и темы для обсуждения, по возможности предусмотреть возможные «тупики» в беседах и способы их предотвращения. Следовательно, интерактивное обучение - это особая форма организации образовательного процесса, цель которой заключается в создании комфортных педагогических условий в высшей школе, способствующих обретению студентом уверенности в своей интеллектуальной деятельности и повышению продуктивности образовательного процесса в целом.

Исходя из вышесказанного, можно сделать вывод, что интерактивное обучение является одним из способов приобретения слушателями новых знаний, который становится возможным только благодаря активному взаимодействию преподавателя со слушателями и слушателей между собой. Главная роль в интерактивной форме контактной работы отводится познавательному процессу обучающихся. Преподаватель же создает комфортные условия для проявления студентами инициативы и организует образовательный процесс (Мухина, 2013: 17). В круг задач педагога входит определение целей, подготовка сценария занятия, фонда оценочных средств. Отдельно уточняется значимость самостоятельной работы студентов. Она не должна быть хаотичной и должна носить системный характер, уделяя внимание как освоению теоретической части курса, так и практическим заданиям, проектной, аналитической деятельности и т. п.

Интерактивные методы, в свою очередь, подразделяются на игровые и неигровые. Игровые направлены на решение ситуационных задач, отработку проблемы в конкретных условиях и включают в себя ролевые игры, кейсы, деловые игры, тренинги профессионального и психологического характера:

- $\quad$ Ролевая игра позволяет участникам с четко заданными ролями проиграть некую профессиональную ситуацию. Это формирует у обучающихся навыки решения профессиональных задач в нетрадиционных условиях среды с учетом особенностей позиции, занимаемой каждым студентом;

- Решение кейсов прежде всего основывается на групповом характере принятия решений в заданной ситуации.Этот метод позволяетучастникам проявить аналитические способности и получить ценный опыт в решении конкретных проблем в профессиональной сфере;

- Деловая игра моделирует проблемную ситуацию по определенным правилам, не задавая ограничений в процессе столкновения выражаемых оппонентами позиций. Она может проецировать как ситуации из профессиональной деятельности, так и проблемы, возникающие при социальном взаимодействии, тем самым стирая грань между теоретическим знанием и его применением в работе;

- Профессиональный тренинг направлен на формирование у обучающихся конкретных навыков, необходимых для применения новейших технологий в процессе решения профессиональных задач.

Среди неигровых форм интерактивного обучения можно выделить практические занятия, семинары, коллоквиумы и т. д. Они базируются на дискуссиях, 
групповых обсуждениях, анализе недочетов и допущенных ошибок, изучении вопросов практического характера.

Таким образом, в процессе методического обеспечения интерактивных форм контактной работы, деятельность педагога делится на пять этапов подготовки и проведения интерактивных занятий в вузах:

Первый этап - определение цели будущего занятия. Преподаватель определяет цель еще на этапе календарного планирования на семестр. Так, целью решения кейсов может быть формирование практического навыка решения задачи, возникшей в профессиональной среде, посредством активного участия группы в выбор наиболее удачного хода развития ситуации и анализ соответствия ответа решению, принятому компанией в реальности. Целью деловой игры, в свою очередь, будет практическая отработка полученных умений при помощи моделирования профессиональной ситуации. Целью интерактивного коллоквиума может являться оценка результатов самостоятельной работы обучающихся по изучению теоретических аспектов имеющейся темы.

Второй этап - подготовительный. Подготовка к занятию подразумевает работу преподавателя по подбору темы занятия, проблемной ситуации, составления списка дефиниций. При разработке занятия учитываются такие факторы как возраст, интересы, направление подготовки студентов, и уровень их вовлеченности в проблему. Необходимыми условиями успешной подготовки занятия являются определение поставленной цели, подготовка программы и раздаточных материалов (словарь определений, графики, схемы, иллюстрации), проверка необходимого оборудования, а также наличие доверительных или нейтральных отношений в студенческой группе. Еще до начала занятия преподаватель готовит задания, предназначенные для самостоятельного выполнения, в то время как обучающиеся знакомятся с материалом по теме, изучают предложенные источники и статьи, готовят презентации, делают заготовки возможных способов решения поставленной проблемы и т. д.

Третий этап - постановочный. Он является непосредственной частью интерактивного занятия и состоит из приветствия, сообщения темы и цели занятия. Слушатели получают задание и дополнительные материалы. Обучающимся предлагается ознакомиться с проблемой, решение которой они должны разработать в ходе занятия. Преподаватель сообщает временные рамки, проводит инструктаж о правилах работы в группе: проявлять активность и доброжелательность, уважать собеседников и их позицию, сохранять открытость для взаимодействия, придерживаться регламента, проявлять творческий подход, применять критическое мышление в поисках истины и т. п. Во избежание недопонимания и путаницы оговаривается и уточняется понятийный аппарат изучаемой темы. Это позволяет студентам выработать привычку попутного выяснения значения малознакомой терминологии, заставляет систематически обращаться к справочной литературе.

Четвертый этап - интерактивный. Характеристики и особенности этой части варьируются и определяются, прежде всего, формой интерактивного обучения, выбранной педагогом. Так, интерактивный этап может включать в себя анализ предложенной ситуации, исследование корпоративной этики компании, поиск разнообразных вариантов решения возникших проблем, моделирование профессиональной ситуации, ответ на вопросы преподавателя по заданной теме, 
выступление с докладом или презентацией, перекрестный опрос, выполнение практических заданий, дискуссии и споры. Позиции участников следует определять в четкой и корректной форме. Интерактивное позиционирование обучающихся основано на осмыслении общего содержания их позиций и формировании новых позиций и взглядов, базирующихся на использованных аргументах, фактах и доводах.

Последний, пятый этап - оценочный. Он предполагает обращение внимания студентов внутрь самих себя, на сознание, восприятие и эмоции, испытанные в процессе интерактивного занятия. Данный этап позволяет выявить отношение участников к содержанию используемых методик, злободневности предложенной темы и т. д. Обучающимся может быть предложено порассуждать о впечатлениях от проведенного занятия, мнениях, которые их удивили, ценностях и стереотипах, на которые они опирались в выборе аргументов, оценке действий участников группы, возможных изменениях в организации интерактивных занятий и т. п. (Панфилова, 2009: 151). Итогом рефлексии станут коллективные выводы, сделанные студентами при помощи вектора, заданного наводящими вопросами педагога. Педагог выставляет оценки в зависимости от степени вовлеченности и результатов работы каждого отдельно взятого студента.

Таким образом, предложенный алгоритм проведения интерактивного занятия в высшей школе состоит из определения основных целей, программы, регламента и источников, примерного сценария планируемого занятия, практических заданий для самостоятельного выполнения и критериев оценки проделанной работы. Педагогу следует обратить особое внимание на создание безопасной психологической среды, в которой студенты смогут активно проявлять творческий подход к решению нестандартных проблем и применять полученные знания на практике для повышения интенсивности развития интеллектуальных, эмоциональных свойств личности, среди которых можно выделить устойчивость внимания, склонность к наблюдению, способность к анализу и критическому мышлению. При соблюдении вышеуказанных условий применение интерактивных форм обучения в высшей школе поможет будущим выпускникам должным образом развить коммуникативные способности и навыки, активизировать творческое начало и установить эмоциональную связь между участниками группы, окажет благоприятное влияние на расширение спектра образовательных возможностей в целом.

\section{СПИСОК ЛИТЕРАТУРЫ}

Двуличанская, Н. Н. (2011) Интерактивные методы обучения как средство формирования ключевых компетентностей // Электронное научно-техническое издание «Наука и образование». № 4 [Электронный ресурс] http://technomag.edu. ru/doc/172651.html (дата обращения: 28.04.2019).

Кругликов, В. Н. (1998) Активное обучение в техническом вузе: теория, технология, практика. ВИТУ. 308 с.

Кругликов, В.Н.(2013) Интерактивное обучение в высшей школе: проблемы и перспективы // Научно-технические ведомости СПбГУ. № 4. С. 66-72.

Панина, Т.С., Вавилова, Л.Н. (2008) Современные способы активизации обучения. 4-е изд., стер. М. 176 с. 
Панфилова А. П. (2009) Инновационные педагогические технологии: Активное обучение: учеб. пособие для студ. высш. учеб. Заведений. М. : Издательский центр «Академия». 192 с.

Солодухина, О. А. (2011) Классификация инновационных процессов в образовании // Среднее профессиональное образование. № 10. С. 12-13.

Мухина, Т. Г. (2013) Активные и интерактивные образовательные технологии (формы проведения занятий) в высшей школе: учебное пособие. ННГАСУ. 97 с.

Дата поступления: 30.03.2020 2.

Мамчук Валерия Геннадьевна - магистрант кафедры педагогики и психологии высшей школы Московского гуманитарного университета. Адрес: 111395, Россия, г. Москва, ул. Юности, д. 5. Тел.: +7 (499) 374-74-59. Эл. адрес: vmamchuk@mosgu. ru. Научный руководитель - д-р пед. н., профессор В. А. Ситаров.

Mamchuk Valeriya Gennadyevna, Graduate Student, Department of Pedagogy and Psychology of Higher School, Moscow University for the Humanities. Postal address: 5, Yunosti St., Moscow, Russian Federation, 111395. Tel.: +7(499)374-74-59. E-mail: vmamchuk@mosgu.ru. Scientific Adviser - V. A. Sitarov, Doctor of Pedagogy, Professor.

\section{Для цитирования:}

Мамчук В. Г. Методическое обеспечение интерактивных занятий в высшей школе // Научные труды Московского гуманитарного университета. 2020. №2. C. 14-19. DOI: 10.17805/ trudy.2020.2.3 